\title{
Oral Cancer around Dental Implants Appearing in Patients with $\backslash$ without a History of Oral or Systemic Malignancy: a Systematic Review
}

\author{
Ginnady Pinchasov ${ }^{1}$, Haim Haimov ${ }^{1}$, Monika Druseikaite ${ }^{1}$, Daniel Pinchasov ${ }^{1}$, Inesa Astramskaite ${ }^{1}$, \\ Rafael Sarikov ${ }^{1}$, Gintaras Juodzbalys ${ }^{1}$ \\ ${ }^{1}$ Department of Oral and Maxillofacial Surgery, Lithuanian University of Health Sciences, Kaunas, Lithuania.
}

Corresponding Author:

Ginnady Pinchasov

Siaures 103-21, LT-49238, Kaunas

Lithuania

Phone: +37064333569

E-mail: gabriel.genady@gmail.com

\begin{abstract}
Objectives: The purpose of this article is to systematically review the circumstance of oral cancer around osseointegrated dental implants.

Material and Methods: An electronic literature search was conducted through the MEDLINE (PubMed) and EMBASE databases. The search was restricted for articles published during the last 21 years from January 1996 to April 2017 and articles were limited to English language.

Results: A total of 35 articles were reviewed, and 19 of the most relevant articles that are suitable to the criteria were selected. Case reports were analysed when oral cancer was present in patients with dental implants. Finally, the present data included 28 patients.

Conclusions: A direct link between dental implants and oral cancer was not found. It was observed that there were no significant differences in number of incidences of oral cancer between patients with history of malignancy and those without. More research should be made to document such cases. It was noticed that in many cases oral cancer around dental implant present itself as peri-implantitis, correct differential diagnosis is essential in such cases.
\end{abstract}

Keywords: cancer; dental implants; inflammation; oral cancer; peri-implantitis; squamous cell carcinoma.

Accepted for publication: 26 September 2017

To cite this article:

Pinchasov G, Haimov H, Druseikaite M, Pinchasov D, Astramskaite I, Sarikov R, Juodzbalys G.

Oral Cancer around Dental Implants Appearing in Patients with/without a History of Oral or Systemic Malignancy: a Systematic Review

J Oral Maxillofac Res 2017;8(3):e1

URL: http://www.ejomr.org/JOMR/archives/2017/3/e1/v8n3e1.pdf

doi: $10.5037 /$ jomr.2017.8301 


\section{INTRUDUCTION}

Oral cancer, also known as mouth cancer, is a type of head and neck cancer and is any cancerous tissue growth located in the oral cavity [1]. It may arise as a primary lesion originating in any of the tissues in the mouth, by metastasis from a distant site of origin, or by extension from a neighbouring anatomic structure, such as the nasal cavity. Alternatively, the oral cancer may originate in any of the tissues of the mouth, and may be of varied histologic types: teratoma, adenocarcinoma derived from a major or minor salivary gland, lymphoma from tonsillar or other lymphoid tissue, or melanoma from the pigmentproducing cells of the oral mucosa. There are several types of oral cancers, but around $90 \%$ are squamous cell carcinomas (SCC), [2] originating in the tissues that line the mouth and lips. Oral or mouth cancer most commonly involves the tongue. It may also occur on the floor of the mouth, cheek lining, gingiva (gums), lips, or palate (roof of the mouth). Most oral cancers look very similar under the microscope and are called SCC, but less commonly other types of oral cancer occur, such as Kaposi's sarcoma. It is well documented that oral SCC related to risk factors such as smoking and alcohol consumption as well as premalignant lesions and conditions such as leukoplakia, oral lichen planus (OLP), and previous malignancy of the upper respiratory system and gastrointestinal tract. Osseointegrated dental implants are rarely reported in association with oral SCC [3] . Rehabilitation using dental implants has become a popular treatment option and with its popularity there is an increased in implant related complications with emphasis on inflammatory processes that affect the bone and soft tissues which may require a differential diagnosis from malignant lesions. Also it is reported in the literature that in some types of cancer it has been shown that chronic inflammation play a role in cancer development [4]. In this study, we discuss the hypothesis of such principle in regard to chronic inflammation around dental implants. Presented here a review of the cases published in the literature on oral carcinomas in connection with dental implants and it was examined whether there is direct relationships between the complications arrive from dental implants and the development of oral cancer.

\section{MATERIAL AND METHODS Protocol and registration}

Analysis and inclusion criteria methods were specified in advance and documented in a protocol. The review was registered in an international prospective register of systematic reviews 'PROSPERO' [ 5 ].

The protocol (registration No.: CRD42017067200), can be accessed through the following link:

http://www.crd.york.ac.uk/PROSPERO/display record.asp? ID $=$ CRD42017067200

\section{Focus question}

The focus question developed according to the problem, intervention, comparison, outcome and study design (PICO) is presented in Table 1.

\section{Question}

What is the association between oral cancer appearances around dental implants in patients with without a history of oral or systemic malignancy?

\section{Types of publications}

The review included case reports, case reviews, retrospective and prospective studies that were published in the English language on humans. The excluded articles were in non-English language and abstracts lacking full text.

\section{Types of studies}

The review included any case reports that presented with the relevant criteria.

Table 1. PICOS guidelines

\begin{tabular}{l|l}
\hline \multicolumn{1}{c|}{ Component } & \multicolumn{1}{c}{ Description } \\
\hline $\mathbf{P}$ (problem) & Oral cancer \\
\hline I (intervention/indicator) & Chronic inflammation around dental implants \\
\hline $\mathbf{C}$ (comparison) & Comparison between patients with $\backslash$ without a history of oral or systemic malignancy \\
\hline $\mathbf{O}$ (outcome of interest) & Oral cancer prevention $\backslash$ early diagnosis \\
\hline Focus question & $\begin{array}{l}\text { What is the association between oral cancer appearances around dental implants in patients with } \backslash \text { without } \\
\text { a history of oral or systemic malignancy? }\end{array}$ \\
\hline
\end{tabular}




\section{Information sources}

The information sources were the MEDLINE (PubMed) and EMBASE databases.

\section{Population}

Case reports included human adults treated with dental implants as a rehabilitation of first and secondary adentia.

\section{Literature search strategy}

According to the PRISMA guidelines [6] an electronic search was conducted using MEDLINE (PubMed) and EMBASE databases, in order to locate case reports concerning oral cancer and dental implants. The keywords used for the search included: "dental implants" AND "squamous cell carcinoma" OR "dental implants" AND "oral cancer" OR "periimplantitis" AND "oral cancer" OR "inflammation" AND "cancer". The search was restricted to English language and articles published from January 1996 to April 2017.

\section{Inclusion and exclusion criteria Inclusion criteria for the selection}

The full text articles with possible relevance were assessed with the following inclusion criteria:

- Case reports of patients that presented oral cancer around osteointegrated dental implants.

- Humans only, adults.

- Patients who classified as pre-malignant.

- All suspected oral cancer must be confirmed by histologic examination.

- Minimum follow-up of 6 months after implant placement.

\section{Exclusion criteria for the selection}

- Articles without sufficient information such as relevant patient anamnesis and etc.

- Articles that were not published in dental journals.

- Dental implants articles which were part of a big rehabilitation after and due to a previous oral cancerous condition.

- Articles where the implants were not dental implants.

- Articles where the implants were not titanium alloy based implants.

\section{Sequential search strategy}

The selected articles were subjected independently to clear inclusion and exclusion criteria by seven reviewers as follows. The seven reviewers resolved differences obstacles through discussion and consulting a third party who was an experienced senior reviewer. Following the initial literature search, all article titles were chosen according to title relevancy, considering the exclusion criteria. Following, studies were excluded based on irrelevant data obtained from the abstracts. The final stage of screening involved reading the full texts and confirming each study's eligibility based on the inclusion criteria.

\section{Data extraction}

The data were independently extracted from studies in the form of variables, according to the aims and themes of the present review, as listed onwards.

\section{Data items}

Data were collected from the included articles and arranged in the following fields:

- "Author" - revealed the author.

- "Year"- revealed the year of publication.

- "Number of patients"- number of patients included in the review.

- "Diagnosis"- patient diagnosis.

- "Mimicking peri-implantitis"- relevant to clinical manifestation of symptoms.

- "History of cancer/pre-malignancy"- relevant to patients history of cancer.

- "Habits"- relevant to habits such as smoking and alcohol consumption.

\section{Checklist for case reports}

The Joanna Briggs Institute critical appraisal tools for use in JBI systematic reviews were used to assess the quality of the studies and to identify papers with intrinsic flaws that could affect the cumulative evidence [7]. Risk of bias assessment parameters:

- Were patient's demographic characteristics clearly described? (Yes/No/NA);

- Was the patient's history clearly described and presented as a timeline? (Yes/No/NA);

- Was the current clinical condition of the patient on presentation clearly described? (Yes/No/NA);

- Was the current clinical condition of the patient on presentation clearly described? (Yes/No/NA);

- Was/were the intervention(s) or treatment procedure(s) clearly described? (Yes/No/NA);

- Was the post-intervention clinical condition clearly described? (Yes/No/NA); 
- Were adverse events (harms) or unanticipated events identified and described? (Yes/No/NA);

- Does the case report provide takeaway lessons? (Yes/No/NA).

\section{RESULTS}

\section{Study selection}

The search delivered 230 search results, from which 35 abstracts were examined (Figure 1). A total of 19 articles were ultimately reviewed in full. Preliminary exclusion was made by the title and its relevancy and later by abstract relevancy. Finally, studies which did not meet the inclusion criteria were filtered. Nineteen studies met the inclusion criteria and the presented data. Finally, the presented data included 28 patients.

\section{Study exclusion}

The reason for excluding studies after full-text

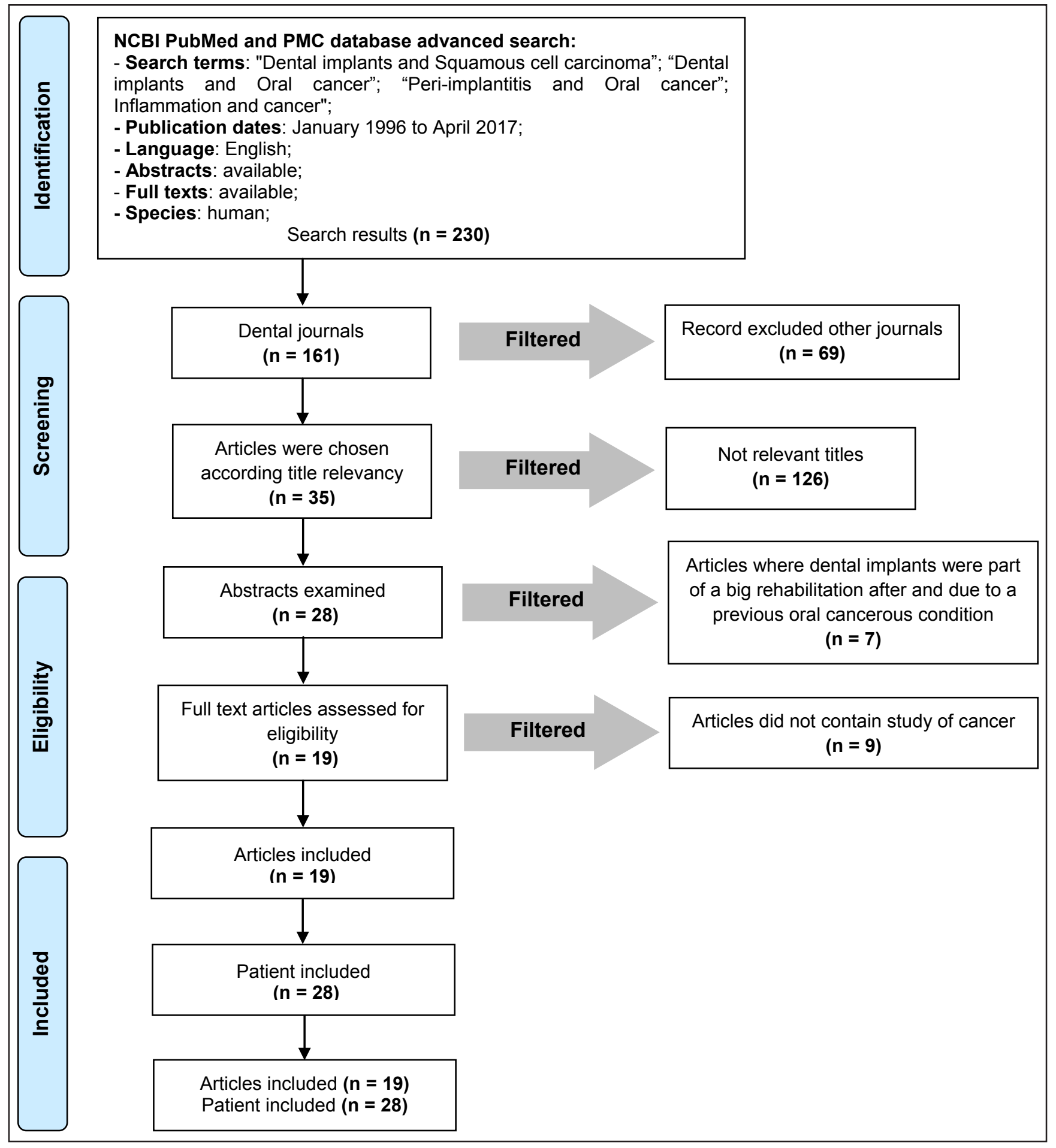

Figure 1. Flow diagram of studies selection according PRISMA guidelines. 
assessment was as follows: articles [7-13] where dental implants were part of a big rehabilitation after and due to a previous oral cancerous condition.

\section{Quality assessment}

The quality assessment of the included studies revealed an unknown risk of bias (for one or more key domains) for the all of the included studies [14-32] (Table 2).

\section{Study characteristics \\ Patients with prior history of malignant or premalignant condition}

In total it was found that in total 13 patients had some type of history of malignancy or premalignant condition $[\underline{14-16}, \underline{18}, \underline{20}, \underline{21}, \underline{24}, \underline{27}, \underline{31}]$. This data was extracted out of a total of 28 patients (Table 3 ).

The first reported cases found in regard to oral cancer and implant presence were in 1996 by Clapp et al. [14] reported unusual series of 3 cases of SCC arising around an implant. One case presented a prior history of malignancy. The second reported case found in regard to oral cancer and implant presence was in 1997 by Moxley et al. [15] the study presented a case report of SCC developing in conjunction with mandibular staple implant. One might argue that staple implant should not be included in the inclusion criteria because it is not a standard implant, but we decided that the proposed mechanism for malignancy is the same and thus the study is eligible for this paper. Block and Scheufler [16] reported a case in 2001 of SCC appearing as peri-implant bone loss. The patient was an exsmoker and had a history of verrucous carcinomas. It was the first case reported when we can observe the problem of malignancy being camouflaged as peri-implantitis and it illustrates the need of careful assessment of peri-implant changes of patients with history of oral cancer. In 2006, Czerninski et al. [18] presented two cases of oral SCC adjacent to dental implants in patients at risk for oral cancer, in one case it was a heavy smoker with OLP and the other had a history of previous oral and colon cancer. They also empathized that patients at risk for oral cancer, especially those with multiple existing risk factors that present with failing dental implants, should be thoroughly evaluated to rule out the presence of malignancy disguised as periimplant disease. In 2007, Abu El-Naaj et al. [20] published two cases which also as in the previous studies initially mimicked peri-implantitis. The first case: a 72 year-old patient, smoker, presented with chronic lichen planus; he was carrying two implants supporting an over denture with ballattachments, placed 15 years before. He presented with an ulcerated symphyseal tumour and bone loss around implant in position \#43. The implant had been spontaneously pushed out. The second case: A 70 year-old woman presented with an exophytic tumour developed around dental implants placed in the anterior part of the mandible. Panoramic X-rays showed major osteolysis, especially around the distal abutment implants. In both cases the diagnosis was SCC. It was recommended by the author that patients with risk factors for SCC (smoking or alcohol consumption, precancerous lesions) are an indication for a permanent follow-up. Biopsies should prove the diagnosis. In 2008, Kwok et al. [21] presented three case reports. The first case concerned a 62-year-old male with a history of high consumption of tobacco and alcohol. The patient was treated with 8 implants. An ulcer was found in the lower right premolar area. Biopsy was taken and revealed a well-differentiated carcinoma. The second case concerned a 71-year old male, a heavy alcohol consumer and an exsmoker. He was treated with 2 implants in the lower incisor area. An ulcer appeared 6 years after the treatment which resulted to be a well-differentiated SCC. In the case presented by Gallego et al. [24] an 81-year-old edentulous woman with history of OLP developed an in situ SCC on the left mandibular edentulous ridge. There were not any risk factors. The patient was treated with a marginal mandibular resection and rehabilitated with implants. One year later, the patient developed a recurrence over the resected area, requiring segmental mandibulectomy. This case report, as other studies that are presented in this review, demonstrates that recurrent primary malignancy can masquerade as benign peri-implant complications. A high degree of attentiveness is required in the follow-up of patients with previous cancer or premalignant lesions. Another case of oral cancer camouflaged as peri-implantitis was in 2009 by Gulati et al. [27] The case presented was of a 62-year-old woman who presented with a white patch in the oral cavity, diagnosed to be a SCC. She went through surgical reconstruction with micro vascular fibula graft. The patient had undergone posterior implant treatment for the prosthetic rehabilitation. Repeated events of peri-implantitis lead to biopsy in the inflamed area, which resulted to a diagnosis of oral SCC. In 2015, Favia et al. [31] reported a case of a 66-year-old female patient, who had received intravenous bisphosphonates for bone breast cancer metastases. The patient came for a non-implant surgery-triggered PI-MRONJ. 
Table 2. Quality assessment

\begin{tabular}{|c|c|c|c|c|c|c|c|c|}
\hline Author & $\begin{array}{c}\text { Were patient's demographic } \\
\text { characteristics clearly } \\
\text { described? }\end{array}$ & $\begin{array}{l}\text { Was the patient's history } \\
\text { clearly described and } \\
\text { presented as a timeline? }\end{array}$ & $\begin{array}{c}\text { Was the current clinical } \\
\text { condition of the patient on } \\
\text { presentation clearly described? }\end{array}$ & $\begin{array}{c}\text { Was the current clinical } \\
\text { condition of the patient on } \\
\text { presentation clearly described? }\end{array}$ & $\begin{array}{l}\text { Was the intervention(s) } \\
\text { or treatment procedure(s) } \\
\text { clearly described? }\end{array}$ & $\begin{array}{l}\text { Was the post-intervention } \\
\text { linical condition clearly } \\
\text { described? } \\
\end{array}$ & $\begin{array}{l}\text { Were adverse events (harms) } \\
\text { or unanticipated events } \\
\text { identified and described? }\end{array}$ & $\begin{array}{c}\text { Does the case report } \\
\text { provide takeaway } \\
\text { lessons? } \\
\end{array}$ \\
\hline Clapp et al. [14] & NA & Yes & Yes & Yes & No & NA & NA & No \\
\hline Moxley et al. [15] & NA & Yes & Yes & Yes & No & NA & $\mathrm{NA}$ & No \\
\hline Block and Scheufler $[16]$ & NA & Yes & Yes & Yes & Yes & $\mathrm{NA}$ & $\mathrm{NA}$ & Yes \\
\hline Shaw et al. [17] & NA & No & Yes & Yes & Yes & $\mathrm{NA}$ & $\mathrm{NA}$ & Yes \\
\hline Czerninski et al. [18] & NA & Yes & No & Yes & No & $\mathrm{NA}$ & $\mathrm{NA}$ & Yes \\
\hline Dib et al. [19] & NA & Yes & Yes & Yes & Yes & $\mathrm{NA}$ & $\mathrm{NA}$ & No \\
\hline Abu El-Naaj et al. [20] & NA & Yes & Yes & Yes & Yes & $\mathrm{NA}$ & $\mathrm{NA}$ & Yes \\
\hline Kwok et al. [21] & NA & Yes & Yes & Yes & No & $\mathrm{NA}$ & $\mathrm{NA}$ & No \\
\hline Schache et al. [22] & $\mathrm{NA}$ & Yes & Yes & Yes & No & $\mathrm{NA}$ & $\mathrm{NA}$ & No \\
\hline Chimenos-Küstner et al. [23] & $\mathrm{NA}$ & Yes & Yes & Yes & No & $\mathrm{NA}$ & $\mathrm{NA}$ & Yes \\
\hline Gallego et al. [24] & NA & Yes & Yes & Yes & No & $\mathrm{NA}$ & $\mathrm{NA}$ & Yes \\
\hline Eguia del Valle et al. [25] & NA & Yes & Yes & Yes & No & $\mathrm{NA}$ & $\mathrm{NA}$ & Yes \\
\hline McGuff et al. [26] & NA & Yes & No & Yes & No & $\mathrm{NA}$ & $\mathrm{NA}$ & No \\
\hline Gulati et al. [27] & NA & No & No & Yes & No & $\mathrm{NA}$ & NA & Yes \\
\hline De Ceulaer et al. [28] & NA & Yes & Yes & No & No & $\mathrm{NA}$ & $\mathrm{NA}$ & Yes \\
\hline Bhatavadekar [29] & $\mathrm{NA}$ & Yes & Yes & Yes & Yes & $\mathrm{NA}$ & $\mathrm{NA}$ & No \\
\hline \begin{tabular}{|l|l} 
Jané-Salas et al. [30] \\
\end{tabular} & $\mathrm{NA}$ & Yes & No & Yes & No & $\mathrm{NA}$ & $\mathrm{NA}$ & Yes \\
\hline Favia et al. [31] & NA & Yes & Yes & No & No & $\mathrm{NA}$ & $\mathrm{NA}$ & No \\
\hline Raiser et al. [32] & $\mathrm{NA}$ & Yes & Yes & Yes & No & NA & NA & Yes \\
\hline
\end{tabular}

$\mathrm{NA}=$ not applicable

Table 3. Characteristics of included studie

\begin{tabular}{|c|c|c|c|c|c|c|}
\hline Author & $\begin{array}{c}\text { Year of } \\
\text { publication }\end{array}$ & $\begin{array}{c}\text { Number of } \\
\text { patients }\end{array}$ & Habits & Diagnosis & $\begin{array}{c}\text { Mimicking } \\
\text { peri-implantitis }\end{array}$ & $\begin{array}{c}\begin{array}{c}\text { History of } \\
\text { cancer/pre-malignancy }\end{array} \\
\end{array}$ \\
\hline Clapp et al. [14] & 1996 & 3 & \multirow{2}{*}{ NA } & \multirow{5}{*}{ SCC } & \multirow{2}{*}{$\mathrm{NA}$} & $\begin{array}{l}2 \text { patients positive; } \\
1 \text { patient negative }\end{array}$ \\
\hline Moxley et al. [15] & 1997 & 1 & & & & Positive \\
\hline Block and Scheufler [16] & 2001 & 1 & ES & & \multirow{3}{*}{ Yes } & Postitue \\
\hline Shaw et al. [17] & 2004 & 2 & NA & & & Negative \\
\hline Czerninski et al. [18] & 2006 & 2 & $1 / 2$ heavy smoker & & & Positive \\
\hline Dib et al. [19] & 2007 & 1 & NA & $\mathrm{AC}$ & NA & Negative \\
\hline Abu El-Naaj et al. [20] & 2007 & 1 & Smoker & \multirow{6}{*}{$\mathrm{SCC}$} & Yes & Positive \\
\hline Kwok et al. [21] & 2008 & 3 & $\begin{array}{l}\text { 2/3 has history of high consumption of } \\
\text { tobacco and alcohol }\end{array}$ & & \multirow{3}{*}{ NA } & $\begin{array}{l}1 \text { patient positive; } \\
2 \text { patients negative }\end{array}$ \\
\hline Schache et al. [22] & 2008 & 1 & NA & & & Neartive \\
\hline Chimenos-Küstner et al. [23] & 2008 & 1 & Moderate ES & & & Negative \\
\hline Gallego et al. [24] & 2008 & 1 & \multirow{9}{*}{ NA } & & \multirow{2}{*}{ Yes } & Positive \\
\hline Eguia del Valle et al. [25] & 2008 & 1 & & & & \multirow{2}{*}{ Negative } \\
\hline McGuff et al. [26] & 2008 & 1 & & $\mathrm{CH}$ & $\mathrm{NA}$ & \\
\hline Gulati et al. [27] & 2009 & 1 & & \multirow{4}{*}{$\mathrm{SCC}$} & \multirow{2}{*}{ Yes } & Positive \\
\hline De Ceulaer et al. [28] & 2010 & 1 & & & & \multirow{3}{*}{ Negative } \\
\hline Bhatavadekar [29] & 2012 & 1 & & & $\mathrm{NA}$ & \\
\hline Jané-Salas et al. [30] & 2012 & 2 & & & No & \\
\hline Favia et al. [31] & 2015 & 1 & & BBCM & $\mathrm{NA}$ & Positive \\
\hline Raiser et al. [32] & 2016 & 3 & & $\begin{array}{l}1 \text { patient BCL, } \\
2 \text { patients SCC }\end{array}$ & Yes & $\begin{array}{l}1 \text { patient negative; } \\
2 \text { patients positive }\end{array}$ \\
\hline
\end{tabular}

$\mathrm{SCC}=$ squamous cell carcinoma; $\mathrm{AC}=$ adenocarcinoma; $\mathrm{CH}=$ chondroblastic osteosarcoma; $\mathrm{BCL}=\mathrm{B}$-cell lymphoma; $\mathrm{NA}=$ not applicable; $\mathrm{BBCM}=$ bone breast cancer metastases; $\mathrm{ES}=$ ex-smoker 
After surgical resection of the necrotic bone, conventional and immunohistochemical examinations were performed, which showed breast cancer deposits within the necrotic bone. It was recommended by the authors that clinicians should be prudent when performing implant surgery in cancer patients with advanced-stage disease and consider the possible occurrence of peri-implant metastases while planning adequate treatments in such patients. In 2016, Raiser et al. [32] reported three cases of patients that presented with asymptomatic lesions around longstanding dental implants that resembled periimplantitis. One case was primary large B-cell lymphoma and the remaining cases were primary SCC in patients with OLP.

\section{Patients without prior history of malignant or premalignant condition}

In this review 15 patients in total showed no history of malignancy and yet presented with SCC. $[\underline{17}, \underline{19}, \underline{21-}$ $\underline{23}, \underline{25}, \underline{26}, \underline{28-30]}$.

As was mentioned before, Clapp et al. [14] presented three cases of SCC arising around an implant, one of the cases did not have a history of risk factors and the third presented with moderate dysplasia of the oral mucosa. In 2004, Shaw et al. [17] described two cases where second primary malignancy in the peri-implant tissues necessitated further major resections. The patients were without a prior history of malignant lesions or risk factors, a 67-year-old male and a 64-year-old female. In both cases, the initial clinical appearance and histology suggested peri-implantitis. These cases exhibit that second primary malignancy can masquerade as benign periimplant complications and that a high degree of caution is required. It was recommended that fixed prostheses should be regularly removed, especially in patients who have field change. In 2007, Dib et al. [19] presented a case where a female patient was referred to the clinic with symptoms of irritation, swelling, and pain associated with implants in the mandible and the maxilla. Clinical examination, $\mathrm{X}$-ray, and histopathology revealed that the patients suffered from a metastatic lesion, primary tumour being an adenocarcinoma of the breast diagnosed at the same time. In 2008, Kwok et al. [21] presented three case reports. Two were discussed in previous chapter. The third case is a 67-year-old female. In 1992, she had a breast tumour which was removed. In 2001 and 2004 she had operations for carcinomas of the tongue. In 2006, granulation tissue was found around dental implant during removal of hyperplastic lesion in the lower lip. After biopsy of the granulation tissue, early stage of SCC adjacent to the implant was found. In 2008, Schache et al. [22] presented a case of a 77-year-old male with no history of cancer and without any known risk factors. Exophytic lesion was found around implants that support a fixed denture. The lesion was found 5 years after implant placement. In 2008, Chimenos-Küstner et al. [23] reported a case of a 62-year-old woman, moderate ex-smoker, who quit smoking tobacco 10 years ago and she was a moderate alcohol consumer, without a prior history of cancer. A few weeks after the implants were inserted in positions \#41 and \#31, she began to develop a fast-growing exophytic lesion around them. The histopathological examination found a moderately well-differentiated SCC. The treatment consisted of partial mandibulectomy and removal of both right and left lymph nodes. It was recommended in the study to use complementary diagnosis tools (imaging, biopsies) before any rehabilitation treatment with implants to prevent similar developments. However, we feel that such recommendations are not realistic for each patient unless he has a prior history of cancer. The other studies presented in this review seem to share a similar point of view to ours. In 2008, Eguia del Valle et al. [25] presented a study, where primary oral SCC arising around dental osseointegrated implants mimicking peri-implantitis. In the case was presented a 76 male patient with no previous history of malignance and no risk factors related to oral cancer. Two implants were placed in the right side of the mandible. The patient exhibited sings of peri-implantitis and curettage was performed. Histopathological examination revealed a welldifferentiated SCC. Also in 2008, in McGuff et al. [26] reported a case of a 38-year-old woman that 11 months after receiving a dental implant developed a low-grade chondroblastic osteosarcoma of the right maxilla. It was recommended that dentists should be aware of such possible complications even if they are rare. In 2010, De Ceulaer et al. [28] presented a case of a 54-year-old white man, after implant placement in the region of tooth \#3; ulceration around the implant site was noticed. The patient stated that before the dental implant placement, he did not notice any oral ulcers. Radiographic examination with an orthopantomogram revealed an area of bone loss around the dental implant. An incisional biopsy of the region was immediately performed, and the histologic examination revealed SCC. In 2012, a case was reported by Bhatavadekar [29] the patient presented was a 54-year-old white man with no history of cancer. The patient had visited his dentist for implant placement in the region of tooth \#3. Over the next several months, he had noticed 
an ulceration around the implant site, with a "slight swelling," which he attributed to his lack of brushing in the region. The patient stated that before the dental implant placement, he had not noticed any oral ulcers, an incisional biopsy of the region was immediately performed, and the histologic examination revealed well-differentiated epithelial cells, with keratin pearl formation, nuclei scattered around central mass, irregular basement membrane, and a superficially invasive nature. These classic histologic features of a low-grade SCC confirmed the diagnosis. Jané-Salas et al. [30] presented two cases in 2012, one of a 42-yearold male. The patient presented partial edentulism in both lower quadrants and was recommended implant placement in areas \#36, \#37, \#46 and \#47 as rehabilitation, which he accepted, and the implants were placed in September of 2007. For various reasons, the patient did not undergo a prosthetic phase and did not come in for a check-up until December 29, 2008, presenting a non-painful, non-bleeding lesion on the right outer edge of the tongue, which the patient attributes to self-traumatism. Slightly hardened edges are observed upon palpation of the lesion, the patient refuses to undergo a biopsy. The patient does not come in for a visit until February 22, 2009 and upon observing the persistence of the lesion with negative cervical palpation the patient undergoes a biopsy and is diagnosed with SCC. The second case has to do with a 79-year-old male, without any relevant medical history, a non-smoker and nondrinker, wearing a full oral implant-supported denture for the past 9 years. Traumatic origin is suspected due to a fracture of the ceramic in the area. The restoration was polished and a follow-up appointment was done after 8 days. During the follow-up visit, an improvement of the lesion is noted and the patient agreed to have 3 additional implants placed in order to redo the lower rehabilitation. The treatment took place on January 25, 2007, observing a small residual lesion in the ulcerated area therefore, an incisional biopsy was performed. The result revealed moderately differentiated oral SCC.

\section{DISSCUSION}

Although inflammation has long been known as a localized protective reaction of tissue to irritation, injury, or infection, characterized by pain, redness, swelling, and sometimes loss of function, there has been a new realization about its role in a wide variety of diseases, including cancer. While acute inflammation is a part of the defence response, chronic inflammation can lead to cancer. Several pro-inflammatory gene products have been identified to mediate a critical role in suppression of apoptosis, proliferation, angiogenesis, invasion, and metastasis. Among these gene products are tumour necrosis factor (TNF) and members of its superfamily, interleukin-1 alpha (IL-1 $\alpha$ ), IL-1 $\beta$, IL-6, IL-8, IL-18, chemokines, matrix metalloproteinase-9, vascular endothelial growth factor, cyclooxygenase-2, and 5-lipoxygenase. The expression of all these genes are mainly regulated by the transcription factor nuclear factor- $\mathrm{kB}$, which is constitutively active in most tumours and is induced by carcinogen (such as cigarette smoke), tumour promoters, and carcinogenic viral proteins [33]. In regard to dental implants, the soft tissue around dental implants is an area that might be going through repeated inflammation. This inflammation might take a part in the development of oral cancer. The reason is the action of cytokine mediators such as: prostaglandins, IL-1, IL-6 and TNF [34]. Schache et al. [22] proposed that implants might provide a route of entry for SCC to the mandible due to the loss of periodontal ligament. We noticed that in most cases when oral cancer arises around dental implants it is when patients had history with some form of cancer. Also habitual consumption of alcohol and tabaco are of important risk factors for oral cancer as seen in many of the studies [14-17]. The perhaps most noted aspect that we discussed here is that in many cases oral cancer presents itself was in the form of periimplant infection. From the results it was evaluated that 13 patients presented with SCC mimicking periimplantitis [16-18,20,24,25,27,28,32].

The importance is in recognizing that in the cases of high risk patients, careful evaluation should be made [14-18]. This is important nowadays especially because in cases of oral dysplasia it is currently impossible to predict accurately which lesions will progress. More accurate markers predicting progression to cancer would enable the targeting of these lesions for more aggressive treatment and closer follow-up, as this was reviewed by Smith et al. [35]. Unfortunately clear biomarkers for oral cancer are yet to be discovered and more research should be done on the subject, until we will have clear biological markers for oral cancer each patient with of oral dysplasia should be evaluated as one with a high risk for cancer especially when dental implant therapy is planned.

\section{CONCLUSIONS}

It was observed that there were no significant differences in number of incidences of oral cancer 
between patients with history of malignancy and those without; however more research should be made to document such cases. A direct link between dental implants and oral cancer was not found. It was found that in many cases oral cancer around dental implant present itself as peri-implantitis. It is highly recommended to take extra care in the evaluation of such symptoms, to be able to perform correct differential diagnosis and in some cases biopsy should be considered.

\section{ACKNOWLEDGMENTS AND DISCLOSURE STATEMENTS}

The authors confirm that this review content has no conflict of interest with any financial organization regarding the material discussed in the review.

\section{REFERENCES}

1. Werning JW. Oral cancer: diagnosis, management, and rehabilitation. 1st Edition. New York: Thieme Medical Publishers, Inc; 2007. p. 1.

2. The Oral Cancer Foundation. Oral Cancer Facts. [URL: www.oralcancerfoundation.org]

3. Czerninski R, Kaplan I, Almoznino G, Maly A, Regev E. Oral squamous cell carcinoma around dental implants. Quintessence Int. 2006 Oct;37(9):707-11. [Medline: 17017632]

4. Aggarwal BB, Shishodia S, Sandur SK, Pandey MK, Sethi G. Inflammation and cancer: how hot is the link? Biochem Pharmacol. 2006 Nov 30;72(11):1605-21. [Medline: 16889756] [doi: 10.1016/j.bcp.2006.06.029]

5. Chien PF, Khan KS, Siassakos D. Registration of systematic reviews: PROSPERO. BJOG. 2012 Jul;119(8):903-5. [Medline: 22703418] [doi: 10.1111/j.1471-0528.2011.03242.x]

6. Moher D, Liberati A, Tetzlaff J, Altman DG; PRISMA Group. Preferred reporting items for systematic reviews and metaanalyses: the PRISMA statement. Int J Surg. 2010;8(5):336-41. [Medline: 20171303] [doi: 10.1016/j.ijsu.2010.02.007]

7. The Joanna Briggs Institute. Joanna Briggs Institute Reviewer's Manual: 2016 edition. Australia: The Joanna Briggs Institute; 2016. [URL: https://joannabriggs.org/]

8. Papi P, Jamshir S, Brauner E, Di Carlo S, Ceci A, Piccoli L, Pompa G. Clinical evaluation with 18 months followup of new PTTM enhanced dental implants in maxillo-facial post-oncological patients. Ann Stomatol (Roma). 2015 Feb 9;5(4):136-41. [Medline: 25774249] [PMC free article: 4333601]

9. Kobayashi Y, Sumida T, Ishikawa A, Mori Y. The Contribution of Dental Implants to Functional Artificial Restoration After Treatment of Oral Cancer. Anticancer Res. 2016 Jun;36(6):3053-6. [Medline: 27272826]

10. Ernst N, Sachse C, Raguse JD, Stromberger C, Nelson K, Nahles S. Changes in Peri-Implant Bone Level and Effect of Potential Influential Factors on Dental Implants in Irradiated and Nonirradiated Patients Following Multimodal Therapy Due to Head and Neck Cancer: A Retrospective Study. J Oral Maxillofac Surg. 2016 Oct;74(10):1965-73. [Medline: 27376183] [doi: 10.1016/j.joms.2016.06.005]

11. Kumar VV, Ebenezer S, Kämmerer PW, Jacob PC, Kuriakose MA, Hedne N, Wagner W, Al-Nawas B. Implants in free fibula flap supporting dental rehabilitation - Implant and peri-implant related outcomes of a randomized clinical trial. J Craniomaxillofac Surg. 2016 Nov;44(11):1849-1858. [Medline: 27697397] [doi: 10.1016/j.jcms.2016.08.023]

12. Takaoka K, Segawa E, Yamamura M, Zushi Y, Urade M, Kishimoto H. Dental implant treatment in a young woman after marginal mandibulectomy for treatment of mandibular gingival carcinoma: a case report. Int J Implant Dent. 2015 Dec;1(1):20. [Medline: 27747642] [PMC free article: 5005787] [doi: 10.1186/s40729-015-0022-2]

13. Cotic J, Jamsek J, Kuhar M, Ihan Hren N, Kansky A, Özcan M, Jevnikar P. Implant-prosthetic rehabilitation after radiation treatment in head and neck cancer patients: a case-series report of outcome. Radiol Oncol. 2016 Feb 7;51(1):94-100. [Medline: 28265238] [PMC free article: 5330162] [doi: 10.1515/raon-2016-0005]

14. Clapp C, Wheeler JC, Martof AB, Levine PA. Oral squamous cell carcinoma in association with dental osseointegrated implants. An unusual occurrence. Arch Otolaryngol Head Neck Surg. 1996 Dec;122(12):1402-3. [Medline: 8956760] [doi: 10.1001/archotol.1996.01890240108024]

15. Moxley JE, Stoelinga PJ, Blijdorp PA. Squamous cell carcinoma associated with a mandibular staple implant. J Oral Maxillofac Surg. 1997 Sep;55(9):1020-2. [Medline: 9294519] [doi: 10.1016/S0278-2391(97)90083-5]

16. Block MS, Scheufler E. Squamous cell carcinoma appearing as peri-implant bone loss: a case report. J Oral Maxillofac Surg. 2001 Nov;59(11):1349-52. [Medline: 11688041] [doi: 10.1053/joms.2001.27532]

17. Shaw R, Sutton D, Brown J, Cawood J. Further malignancy in field change adjacent to osseointegrated implants. Int J Oral Maxillofac Surg. 2004 Jun;33(4):353-5. [Medline: 15145037] [doi: 10.1016/j.ijom.2003.09.017]

18. Czerninski R, Kaplan I, Almoznino G, Maly A, Regev E. Oral squamous cell carcinoma around dental implants. Quintessence Int. 2006 Oct;37(9):707-11. [Medline: 17017632]

19. Dib LL, Soares AL, Sandoval RL, Nannmark U. Breast metastasis around dental implants: a case report. Clin Implant Dent Relat Res. 2007 Jun;9(2):112-5. [Medline: 17535335] [doi: 10.1111/j.1708-8208.2007.00033.x] 
20. Abu El-Naaj I, Trost O, Tagger-Green N, Trouilloud P, Robe N, Malka G, Peled M. [Peri-implantitis or squamous cell carcinoma?]. Rev Stomatol Chir Maxillofac. 2007 Nov;108(5):458-60. [Medline: 17624383] [doi: 10.1016/j.stomax.2007.04.004]

21. Kwok J, Eyeson J, Thompson I, McGurk M. Dental implants and squamous cell carcinoma in the at risk patient--report of three cases. Br Dent J. 2008 Nov 22;205(10):543-5. [Medline: 19023308] [doi: 10.1038/sj.bdj.2008.980]

22. Schache A, Thavaraj S, Kalavrezos N. Osseointegrated implants: a potential route of entry for squamous cell carcinoma of the mandible. Br J Oral Maxillofac Surg. 2008 Jul;46(5):397-9. [Medline: 18063453] [doi: 10.1016/j.bjoms.2007.09.009]

23. Chimenos-Küstner E, López-López J, Finestres-Zubeldia F. Squamous carcinoma after dental Implants: A Clinical Case. Rev Port Estomatol Cir Maxilofac. 2008 Aprl-Jun;49(2):97-100. [doi: 10.1016/S1646-2890(08)70041-4]

24. Gallego L, Junquera L, Baladrón J, Villarreal P. Oral squamous cell carcinoma associated with symphyseal dental implants: an unusual case report. J Am Dent Assoc. 2008 Aug;139(8):1061-5. [Medline: 18682620] [doi: 10.14219/jada.archive.2008.0308]

25. Eguia del Valle A, Martínez-Conde Llamosas R, López Vicente J, Uribarri Etxebarria A, Aguirre Urizar JM. Primary oral squamous cell carcinoma arising around dental osseointegrated implants mimicking peri-implantitis. Med Oral Patol Oral Cir Bucal. 2008 Aug 1;13(8):E489-91. [Medline: 18667981]

26. McGuff HS, Heim-Hall J, Holsinger FC, Jones AA, O’Dell DS, Hafemeister AC. Maxillary osteosarcoma associated with a dental implant: report of a case and review of the literature regarding implant-related sarcomas. J Am Dent Assoc. 2008 Aug;139(8):1052-9. [Medline: 18682619] [doi: 10.14219/jada.archive.2008.0307]

27. Gulati A, Puthussery FJ, Downie IP, Flood TR. Squamous cell carcinoma presenting as peri-implantitis: a case report. Ann R Coll Surg Engl. 2009 Oct;91(7):W8-10. [Medline: 19833011] [PMC free article: 2966169] [doi: 10.1308/147870809X450584]

28. De Ceulaer J, Magremanne M, van Veen A, Scheerlinck J. Squamous cell carcinoma recurrence around dental implants. J Oral Maxillofac Surg. 2010 Oct;68(10):2507-12. [Medline: 20674127] [doi: 10.1016/j.joms.2010.01.023]

29. Bhatavadekar NB. Squamous cell carcinoma in association with dental implants: an assessment of previously hypothesized carcinogenic mechanisms and a case report. J Oral Implantol. 2012 Dec;38(6):792-8. [Medline: 21574824] [doi: 10.1563/ AAID-JOI-D-11-00045]

30. Jané-Salas E, López-López J, Roselló-Llabrés X, Rodríguez-Argueta OF, Chimenos-Küstner E. Relationship between oral cancer and implants: clinical cases and systematic literature review. Med Oral Patol Oral Cir Bucal. 2012 Jan 1;17(1): e23-8. [Medline: 21743414] [PMC free article: 3448182] [doi: 10.4317/medoral.17223]

31. Favia G, Tempesta A, Limongelli L, Crincoli V, Piattelli A, Maiorano E. Metastatic Breast Cancer in MedicationRelated Osteonecrosis Around Mandibular Implants. Am J Case Rep. 2015 Sep 15;16:621-6. [Medline: 26371774] [PMC free article: 4574514] [doi: 10.12659/AJCR.894162]

32. Raiser V, Abu-El Naaj I, Shlomi B, Fliss DM, Kaplan I. Primary Oral Malignancy Imitating Peri-Implantitis. J Oral Maxillofac Surg. 2016 Jul;74(7):1383-90. [Medline: 26973225] [doi: 10.1016/i.joms.2016.02.008]

33. Weitzman SA, Gordon LI. Inflammation and cancer: role of phagocyte-generated oxidants in carcinogenesis. Blood. 1990 Aug 15;76(4):655-63. [Medline: 2200535]

34. Jeng JH, Wang YJ, Chiang BL, Lee PH, Chan CP, Ho YS, Wang TM, Lee JJ, Hahn LJ, Chang MC. Roles of keratinocyte inflammation in oral cancer: regulating the prostaglandin E2, interleukin-6 and TNF-alpha production of oral epithelial cells by areca nut extract and arecoline. Carcinogenesis. 2003 Aug;24(8):1301-15. [Medline: 12807728] [doi: $10.1093 /$ carcin/bgg083]

35. Smith J, Rattay T, McConkey C, Helliwell T, Mehanna H. Biomarkers in dysplasia of the oral cavity: a systematic review. Oral Oncol. 2009 Aug;45(8):647-53. [Medline: 19442563] [doi: 10.1016/j.oraloncology.2009.02.006]

\section{To cite this article:}

Pinchasov G, Haimov H, Druseikaite M, Pinchasov D, Astramskaite I, Sarikov R, Juodzbalys G.

Oral Cancer around Dental Implants Appearing in Patients withlwithout a History of Oral or Systemic Malignancy: a Systematic Review

J Oral Maxillofac Res 2017;8(3):e1

URL: http://www.ejomr.org/JOMR/archives/2017/3/e1/v8n3e1.pdf

doi: $\underline{10.5037 / j o m r .2017 .8301}$

Copyright (C) Pinchasov G, Haimov H, Druseikaite M, Pinchasov D, Astramskaite I, Sarikov R, Juodzbalys G. Published in the JOURNAL OF ORAL \& MAXILLOFACIAL RESEARCH (http://www.ejomr.org), 30 September 2017.

This is an open-access article, first published in the JOURNAL OF ORAL \& MAXILLOFACIAL RESEARCH, distributed under the terms of the Creative Commons Attribution-Noncommercial-No Derivative Works 3.0 Unported License, which permits unrestricted non-commercial use, distribution, and reproduction in any medium, provided the original work and is properly cited. The copyright, license information and link to the original publication on (http://www.ejomr.org) must be included. 